\title{
Merkel cell carcinoma responsive to Etoposide: a case report and brief literature review
}

\author{
Chiara Ancona', Andrea Caff², Giovanni Manfredi Assanto', Stefano Cordio ${ }^{3}$ \\ ${ }^{1}$ Department of Medical Oncology, Policlinico P. Giaccone, University of Palermo, Via del Vespro 129, 90127 Palermo, Italy. \\ ${ }^{2}$ Endocrinology, Department of Clinical and Experimental Medicine, Garibaldi-Nesima Medical Center, University of Catania, Via Palermo 636, 95122 Catania, Italy \\ ${ }^{3}$ Department of Oncology, Garibaldi-Nesima Medical Center, University of Catania, Via Palermo 636, 95122 Catania, Italy.
}

Correspondence to: Dr. Andrea Caff, Endocrinology, Department of Clinical and Experimental Medicine, Garibaldi-Nesima Medical Center, University of Catania, Via Palermo 636, 95122 Catania, Italy. E-mail: caff.andrea@gmail.com

\section{A B S T R A C T}

Merkel cell carcinoma (MCC), first described in 1972, is an aggressive primary cutaneous carcinoma able to incorporate both epithelial and neuroendocrine features. MCC mainly appears in individuals in their eighth decade and it is related to a high mortality rate. The etiology of this rare disease is not well-understood but ultraviolet radiation exposure, immune suppression, and aging have a consistent role in its pathogenesis. Usually, clinical lesions appear as asymptomatic coloured dermal nodules. The tumour can involve lymph nodes but further evaluation with imaging is recommended. The common approach for localized disease is surgical. This work reports a case of an 86-year-old man with locally advanced MCC where, based on clinical experience, oral mono-chemotherapy with single-agent etoposide was chosen as first-line therapy. A complete objective response was achieved in 2 months.

Key words: Merkel cell carcinoma; neuroendocrine; chemotherapy; etoposide

\section{INTRODUCTION}

Merkel cell carcinoma (MCC) is a rare, aggressive, neuroendocrine carcinoma of the skin that originates from Merkel cells of the dermoepidermal junctions, although some recent work proposes pluripotent dermal stem cells to be origin of this neoplasm. ${ }^{[1]}$

The annual incidence is 0.6 per 100,000 persons $^{[2]}$ but is apparently increasing in the last years thanks to more accurate diagnostic pathology techniques, an aging population, increased sun exposure, and improved registry tools.

MCC has a high mortality rate, the overall 5-year survival rates ranging from $30 \%$ to $64 \%{ }^{[3]}$

Males are more often affected than females, the median age at diagnosis being 76 years. ${ }^{[2]}$ It is extremely rare in children, with only a few cases reported in literature.

Ultraviolet radiation exposure, chronic immune suppression (especially from chronic lymphocytic leukemia, human immunodeficiency virus, and prior solid organ transplant) and the Merkel cell polyomavirus are the main risk factors involved in the tumour pathogenesis. ${ }^{[4]}$ Concerning the

\begin{tabular}{|l|l|}
\hline \multicolumn{3}{|c|}{ Access this article online } \\
\hline Quick Response Code: & Website: \\
& www.jcmtjournal.com \\
\cline { 2 - 2 } & \\
\hline
\end{tabular}

latter, many reports described a strong correlation between infection and carcinogenesis, although the presence of the virus itself is not sufficient to induce MCC.

Clinically, the lesion appears as a fast-growing, painless, solitary dermal nodule, firm, non-tender, coloured from red to violet; rarely does it present as an ulceration.

Skin of the face, arms and lower limbs are the most common sites of localization whereas the trunk and oral and genital mucosa are rare. ${ }^{[2]}$

Typical clinical features are summarized in the acronym "AEIOU" proposed by Heath et al. ${ }^{[5]}$ : asymptomatic, expanding rapidly, immunosuppression, older than age 50 and ultraviolet-exposed site.

The approach to disease management includes with a complete physical examination followed by imaging. Treatment strategies are best considered in a multidisciplinary board consultation. The surgical approach, when negative margins are possible and the disease is not disseminated, should be the first choice followed, when the risk assessment contemplates it or

This is an open access article distributed under the terms of the Creative Commons Attribution-NonCommercial-ShareAlike 3.0 License, which allows others to remix, tweak, and build upon the work non-commercially, as long as the author is credited and the new creations are licensed under the identical terms.

For reprints contact: service@oaepublish.com

How to cite this article: Ancona C, Caff A, Assanto GM, Cordio S. Merkel cell carcinoma responsive to Etoposide: a case report and brief literature review. J Cancer Metasta Treat 2016;2:310-2.

Received: 28-07-2016; Accepted: 01-08-2016. 
specific lymph nodes are involved, by adjuvant radiation therapy within 4 weeks. Adjuvant chemotherapy in regional disease could be considered depending on clinical judgment. In cases of disseminated disease, chemotherapy represents first line therapy; the choice of the agents to be taken based on clinical judgment and experience.

Here we present a case of MCC in an elderly man. The patient is consented and agrees with this publication.

\section{CASE REPORT}

An 86-year-old man presented with a purple-violaceous mass with vegetations in the left pre-auricular region, extending to the maxilla and involving the parotid area [Figure 1]. The lesion had been enlarging for more than three months. The patient had no history or evidence of comorbidities, apart from gallbladder stones and allergy to penicillin. An incisional biopsy was performed MCC.

The neoplasm involved dermis and hypodermis; histology showed a dense infiltrate of small tumour cells with hyperchromatic nuclei and lacking cytoplasm. Immunohistochemistry was consistent with the diagnosis of MCC.

The immune histochemical phenotype of the dermallocated malignant cells was characterized by dot-like focal positivity for Cytokeratin 20 (CK20+), diffuse positivity for synaptophysin(+), cytokeratin AE1/AE3, CD99+, and strong nuclear positivity for Ki-67 $(+100 \%)$. There was negative staining for chromogranin, CEA-, TTF1-, CD56-, S100-, CD20-, CD79a-, CD3-, CD23-, CD5-, CD10-, and Cyclin D1-.

The tumour was classified MCC, T2, locally advanced. No other abnormalities were detected in the laboratory

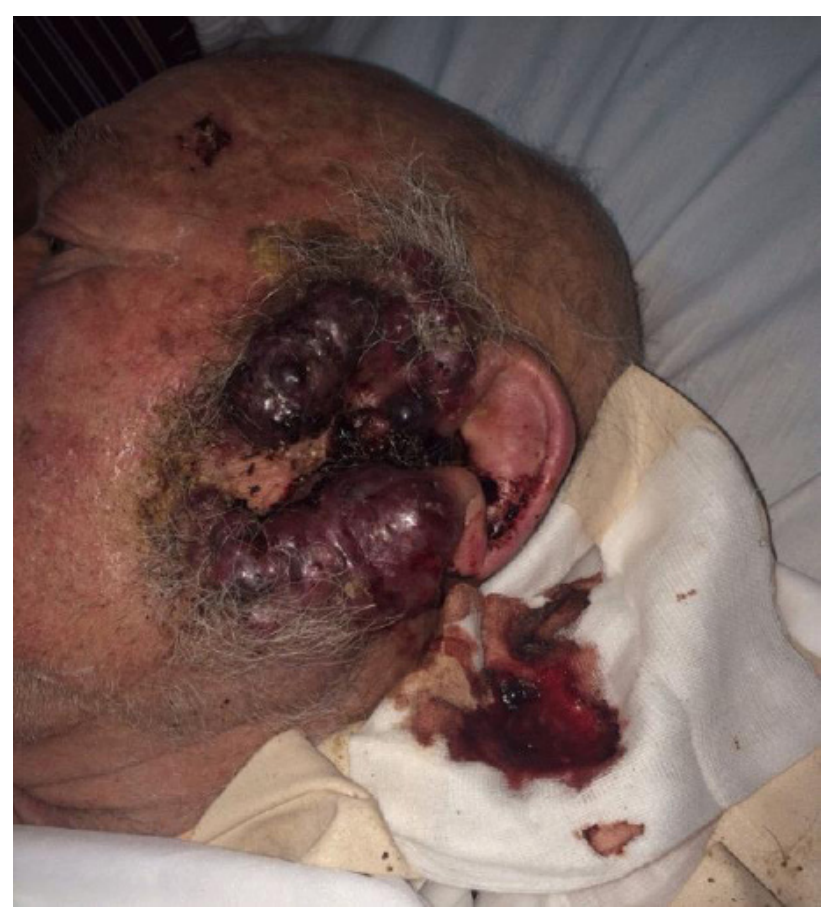

Figure 1: Merkel cell carcinoma at time of first evaluation

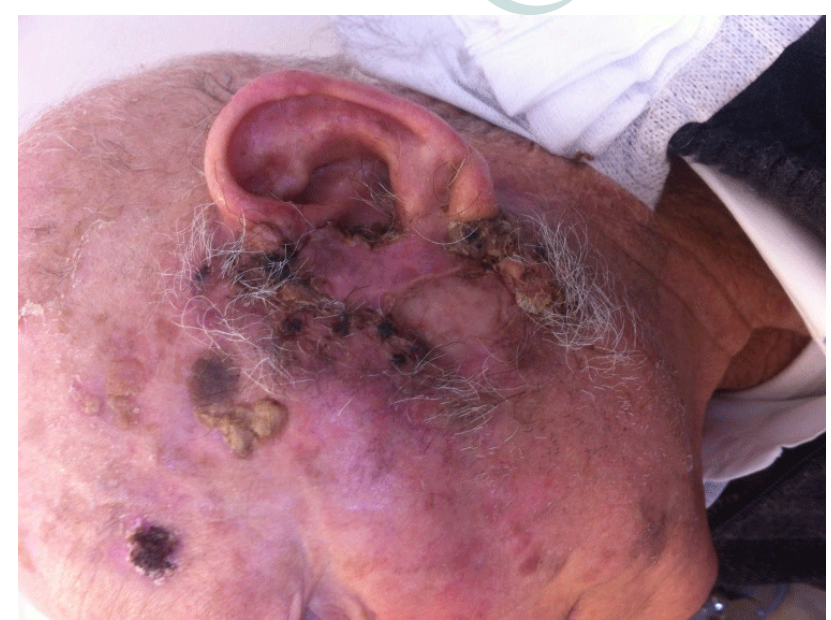

Figure 2: Response to therapy after 1 month of treatment

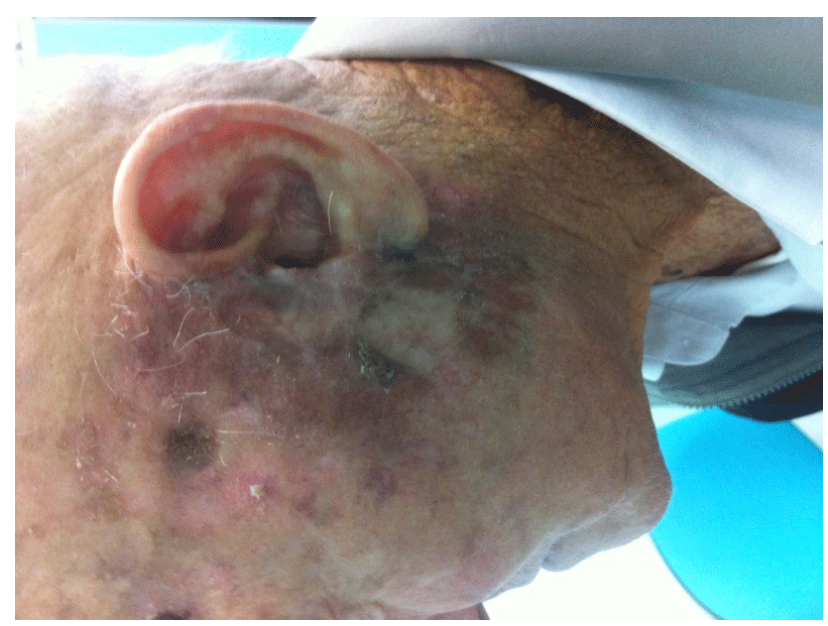

Figure 3: Complete clinical response after 2 months

studies. Computed tomography (CT) scans showed no involvement of local lymph-nodes or distant metastases. Based on these clinical findings, the history, and on his age, an oral chemotherapeutic treatment was proposed. The patient started oral etoposide with the dosage schedule of $50 \mathrm{mg} / \mathrm{m}^{2}$ per 10 days followed by 7 days rest.

After one month of treatment the tumour showed a significant response [Figure 2]. There were side effects or laboratory abnormalities.

By 2 months there was evidence of complete objective response [Figure 3]. Considering the results, therapy was held. Adjuvant radiation was then given.

\section{DISCUSSION}

First described as trabecular carcinoma in 1972 by Toker, ${ }^{[6]}$ MCC represents an aggressive, primary cutaneous carcinoma incorporating both epithelial and neuroendocrine features. The diagnosis is made by clinical evaluation and biopsy, although other small round cell tumors may be considered. For this reason a complete immunohistochemistry panel is needed for the correct diagnosis. Cytokeratin 20 (CK-20), a marker of epithelial origin, is a very sensitive marker for $\mathrm{MCC}^{[7]}$ since it is positive in $89-100 \%$ of cases. Together with negativity of transcription factor 1 (TTF-1), it provides the greatest 
sensitivity and specificity to exclude small cell lung cancer, ${ }^{[8]}$ although $\mathrm{N}$-specific enolase, synaptophysin, and chromogranin-A represent markers of neuroendocrine origin with possible positivity. In our case, pathology and immune-histochemical markers, along with clinical features confirmed the diagnosis.

MCC generally shows a malignant behaviour, with regional lymph-nodes as well as distant metastasis being frequently involved. Twenty-five percent of patients present with lymphadenopathy and 5\% with a distant metastasis. Skin, lung, nervous system, bone, and liver are the most frequent secondary locations. ${ }^{[9]}$ For this reason lymph-nodal examination should be performed. Additionally, PET/CT is often useful for complete staging.

Surgery plays the key role for clinically localized MCC and a complete surgical excision with $2 \mathrm{~cm}$ safety margin, if feasible, seems to be the best treatment approach. Adjuvant radiation with 50 Gy to the tumour bed and regional lymphnodes is also recommended, especially for advanced local and regional disease. ${ }^{[10]}$ When surgery is not feasible, radiation therapy alone, or combined with alternative therapy (e.g., chemotherapy) should be considered.

Presently, there is no first-line chemotherapy established for MCC, since no controlled randomized trials exist. Only retrospective case series and case reports are available.

The chemotherapy regimens used have combined carboplatin or cisplatin with etoposide, cyclophosphamide with vincristine, doxorubicin, bleomycin, or 5-fluorouracil.

Despite a good initial response, early recurrences are the rule. In a retrospective analysis including a wide number of patients, adjuvant chemotherapy was linked to a worse overall survival compared to patients who did not received chemotherapy. ${ }^{[3]}$

In our patient, considering locally advanced disease, age, and patient's history, we decided to start monochemotherapy with oral etoposide.

Previously, one group achieved complete responses in 3 out of $4 \mathrm{MCC}$ patients treated with oral etoposide, two of whom had rather long remissions (16 and 36 months). ${ }^{[11]}$

Our patient achieved a complete objective response in a short period of time. However, long term follow-up is needed to rule out possible recurrence.

\section{Financial support and sponsorship}

Nil.

\section{Conflicts of interest}

There are no conflicts of interest.

\section{REFERENCES}

1. Morrison KM, Miesegaes GR, Lumpkin EA, Maricich SM. Mammalian Merkel cells are descended from the epidermal lineage. Dev Biol 2009;336:76-83.

2. Albores-Saavedra J, Batich K, Chable-Montero F, Sagy N, Schwartz AM, Henson DE. Merkel cell carcinoma demographics, morphology, and survival based on 3870 cases: a population based study. J Cutan Pathol 2010;37:20-7.

3. Lemos BD, Storer BE, Iyer JG, Phillips JL, Bichakjan CK, Fang LC, Johnson TM, Liegeois-Kwon NJ, Otley CC, Paulson KG, Ross MI, Yu SS, Zeitouni NC, Bryd DR, Sondak VK, Gershenwald JE, Sober AJ, Nghiem P. Pathologic nodal evaluation improves prognostic accuracy in Merkel cell carcinoma: analysis of 5823 cases as the basis of the first consensus staging system. J AM Acad Dermatol 2010;67:751-61.

4. Becker JC, Houben R, Ugurel S, Trefzer U, Pfohler C, Schrama D. $\mathrm{MC}$ polyomavirus is frequently present in Merkel cell carcinoma of European patients. J Invest Dermatol 2009;129:248-50.

5. Heath M, Jaimes N, Lemos B, Mostaghimi A, Wang LC, Peñas PF, Nghiem P. Clinical characteristics of Merkel cell carcinoma at diagnosis in 195 patients: the AEIOU features. J AM Acad Dermatol 2008;58:375-81.

6. Toker C. Tarbecular carcinoma of the skin. Arch Dermatol 1972;105:107-10.

7. Scott MP, Helm KF. Cytokeratin 20: a marker for diagnosing Merkel cell carcinoma. Am J Dermatopathol 1999;21:16-20.

8. Hanly AJ, Elgart GW, Jorda M, Smith J, Nadji M. Analysis of thyroid transcription factor-1 and cytokeratin 20 separates merkel cell carcinoma from small cell carcinoma of lung. J Cutan Pathol 2000;27:118-20.

9. Medina-Franco H, Urist MM, Fiveash J, Heslin MJ, Bland KI, Beenken SW. Multimodality treatment of Merkel cell carcinoma: case series and literature review of 1024 cases. Ann Surg Oncol 2001;8:204-8

10. Lebbe C, Becker JC, Grob JJ, Malvehy J, Del Marmol V, Pehamberger H, Peris K, Saiag P, Middleton MR, Bastholt L, Testori A, Stratigos A, Garbe C; European Dermatology Forum (EDF), the European Association of Dermato-Oncology (EADO) and the European Organization for Research and Treatment of Cancer (EORTC). Diagnosis and treatment of Merkel cell carcinoma. European consensus-based interdisciplinary guideline. Eur J Cancer 2015;51:2396-403.

11. Schlaak M, Podewski T, Von Bartenwerffer W, Kreuzberg N, Bangard C, Mauch C, Kurschat P. Induction of durable responses by oral etoposide monochemotherapy in patients with metastatic Merkel cell carcinoma. Eur J Dermatol 2012;22:187-91. 